\title{
Model-based parametric study of frontostriatal abnormalities in schizophrenia patients
}

Shoji Tanaka

\begin{abstract}
Background: Several studies have suggested that the activity of the prefrontal cortex (PFC) and the dopamine (DA) release in the striatum has an inverse relationship. One would attribute this relationship primarily to the circuitry comprised of the glutamatergic projection from the PFC to the striatum and the GABAergic projection from the striatum to the midbrain DA nucleus. However, this circuitry has not characterized satisfactorily yet, so that no quantitative analysis has ever been made on the activities of the PFC and the striatum and also the DA release in the striatum.
\end{abstract}

Methods: In this study, a system dynamics model of the corticostriatal system with dopaminergic innervations is constructed to describe the relationships between the activities of the PFC and the striatum and the DA release in the striatum. By taking published receptor imaging data from schizophrenia patients and healthy subjects into this model, this article analyzes the effects of striatal D2 receptor activation on the balance of the activity and neurotransmission in the frontostriatal system of schizophrenic patients in comparison with healthy controls.

Results: The model predicts that the suppressive effect by D2 receptors at the terminals of the glutamatergic afferents to the striatum from the PFC enhances the hypofrontality-induced elevation of striatal DA release by at most $83 \%$. The occupancy-based estimation of the 'optimum' D2 receptor occupancy by antipsychotic drugs is $52 \%$. This study further predicts that patients with lower PFC activity tend to have greater improvement of positive symptoms following antipsychotic medication.

Conclusion: This model-based parametric study would be useful for system-level analysis of the brains with psychiatric diseases. It will be able to make reliable prediction of clinical outcome when sufficient data will be available.

\section{Background}

Patients with schizophrenia show hypofrontality, which has been suggested to be responsible for cognitive impairment and negative symptoms [1-9]. Hypofrontality is observed even in prodromal stages of schizophrenia, indicating that hypofrontality itself is not sufficient for the onset of symptoms of schizophrenia but is a high-risk or vulnerability marker [10-12]. Therefore, hypofrontality would be a trait-like abnormality that underlies schizophrenia. On the other hand, hyperactivation of the dorsolateral prefrontal cortex (DLPFC) has often been observed during performing a working memory task [13-15]. The occurrence of hyperactivation of the DLPFC seems to be dependent on an intrinsic brain

Correspondence: tanaka-s@sophia.ac.jp

Department of Information and Communication Sciences, Sophia University, Tokyo 102-8554, Japan state as well as task performance and subjective efforts so that the observation has not necessarily been consistent or reproducible. A recent computational analysis of the DLPFC circuit dynamics suggests that the DLPFC circuit tends to be unstable under cortical hypodopaminergic conditions. This could lead to state-dependent variability of DLPFC activation that is considered to be much larger than mere individual differences [16]. Being consistent with this, schizophrenia patients showed much lower test-retest reliability than normal subjects in the working memory activation of the DLPFC, intraparietal sulcus, and insula [17]. It would, therefore, be possible to distinguish seemingly inconsistent hyperactivation of the DLPFC, a state-dependent phenomenon, from trait-like hypofrontality.

The activity of the PFC would have an influence on the activity of the striatum via the glutamatergic 
frontostriatal projection. Hypofrontality would then lead to a decrease in the activity of the striatal medium spiny neurons (MSNs). This would increase the DA concentration in the striatum due to the disinhibition of the DA neurons to which the MSNs send axons. As a consequence, the activity of the PFC and the DA level in the striatum would have a negative correlation, which is consistent with experimental observations [18-21]. Interestingly, the elevated DA levels in schizophrenic patients were associated with the improvement of positive symptoms by antipsychotic medication [22].

Many antipsychotic drugs have been targeting dopamine receptors, especially striatal D2 receptors [23]. Striatal MSNs have D1, D2 and other subtypes of DA receptors on the soma $[24,25]$. There are D2 receptors also at presynaptic terminals of the glutamatergic afferents from the PFC [26,27] as well as on the dopaminergic fibers [26-28]. High densities of D2 receptors in the striatum would enable DA to modulate powerfully the activity of the striatal neurons and information flow through the striatum [29]. It is suggested that DA gates the throughput of sensorimotor and incentive motivational inputs to the striatum and that DA is a "gatekeeper" for glutamate input to the striatum [30]. In schizophrenic patients, striatal DA turnover is elevated [31] and the baseline DA level in the striatum is increased [22]. The elevated levels of DA would overstimulate the $\mathrm{D} 2$ receptors in the striatum. The D2 receptors on the glutamatergic terminals would suppress the glutamatergic input to the striatum from the PFC, which may work as a DA filter of the input $[26,27,32]$. On the other hand, the roles and effects of the activation of DA receptors other than D2 receptors in the corticostriatal system remain less unambiguous. The aim of this article is to analyze how these D2 effects alter the characteristics of the frontostriatal system in patients with schizophrenia and healthy controls by using the receptor binding theory and a circuit model of the frontostriatal system. This article will also explore the possibility of the computational approach in psychiatric research.

\section{Methods}

\section{Receptor binding}

Binding potential (BP) of D2 receptors is given by [33]

$$
B P=\frac{B_{\max }}{K_{d}\left(1+\frac{[D A]}{K_{D A}}\right)}
$$

The symbols used in the above equation and in the following equations are listed in Table 1.

Drugs such as alpha-methyl-p-tyrosine (AMPT), a competitive and reversible inhibitor of tyrosine

\section{Table 1 Symbols used in the model}

\begin{tabular}{|c|c|}
\hline$a$ & $\begin{array}{l}\text { Coefficient that represents the presynaptic suppression of DA } \\
\text { release by the D2 autoreceptor }\end{array}$ \\
\hline$b$ & $\begin{array}{l}\text { Coefficient that represents the presynaptic depression of the } \\
\text { frontostriatal glutamatergic neurotransmission by D2 receptor } \\
\text { activation }\end{array}$ \\
\hline$B_{\max }$ & relative $\mathrm{D} 2$ receptor density \\
\hline$B P_{\text {AMPT }}$ & Binding potential of the D2 receptor after DA depletion \\
\hline$[D A]$ & Extracellular concentration of endogenous DA \\
\hline$[D A]$ & Extracellular concentration of endogenous DA after depletion \\
\hline AMPT & \\
\hline$F$ & $\begin{array}{l}\text { Free synaptic concentration of the administered antipsychotic } \\
\text { drug }\end{array}$ \\
\hline$f(x)$ & Activation function: $f(x)=\tanh (x), x \geq 0$ \\
\hline$K_{A P D}$ & $\begin{array}{l}\text { Dissociation constant of the D2 receptor for the administered } \\
\text { antipsychotic drug }\end{array}$ \\
\hline$K_{d}$ & Dissociation constant of the D2 receptor for the radiotracer \\
\hline$K_{D A}$ & Dissociation constant of the D2 receptors for endogenous DA \\
\hline$P$ & D2 receptor occupancy by endogenous DA \\
\hline$P_{A P D}$ & D2 receptor occupancy by the administered antipsychotic drug \\
\hline $\begin{array}{l}P_{D A} \\
(A P D)\end{array}$ & $\begin{array}{l}\text { D2 receptor occupancy by endogenous DA competing with } \\
\text { the administered antipsychotic drug }\end{array}$ \\
\hline$\tau_{d}$ & Time constant of the DA neurons \\
\hline$\tau_{\varsigma}$ & Time constant of the striatal neurons \\
\hline$\tau_{y}$ & Time constant of DA release \\
\hline$V_{p s}$ & $\begin{array}{l}\text { Normalized connectivity coefficient of the frontostriatal } \\
\text { projection }\end{array}$ \\
\hline$W_{d y}$ & Coefficient representing DA releasability \\
\hline$W_{p s}$ & Connectivity coefficient of the frontostriatal projection \\
\hline$W_{s d}$ & $\begin{array}{l}\text { Connectivity coefficient of the projection from the striatum to } \\
\text { the DA nuclei }\end{array}$ \\
\hline$x_{d}$ & Population activity of the midbrain DA nuclei \\
\hline$x_{p}$ & Population activity of the PFC \\
\hline$x_{5}$ & Population activity of the striatum \\
\hline y & DA release in the striatum: $y=[D A]$ \\
\hline
\end{tabular}

hydroxylase, reduce the extracellular concentration of endogenous DA significantly [22,34]. Comparing the BP before and after the administration of AMPT, we have

$$
\frac{B P}{B P_{A M P T}}=\frac{1+\frac{[D A]_{A M P T}}{K_{D A}}}{1+\frac{[D A]}{K_{D A}}}=\frac{K_{D A}+[D A]_{A M P T}}{K_{D A}+[D A]}
$$

for both schizophrenia patients and healthy controls. In the above equation, we assumed that the $\mathrm{D} 2$ receptor density, $B_{\max }$, did not change by acute administration of AMPT. This has been confirmed in rats [34] but not in humans. In schizophrenia patients, however, there is no reason that the receptor density, $B_{\max }$, is the same with that of healthy controls. Therefore, we distinguish the receptor density of schizophrenia patients (SZ) from that of healthy controls ( $\mathrm{HC}$ ) by using $B_{\max }, s Z$ and 
$B_{\text {max }, H C}$, respectively. Similarly, the extracellular DA concentration is different between patients and healthy controls, which are denoted by $[D A]_{S Z}$ and $[D A]_{H C}$, respectively. The ratio of the $\mathrm{BP}$ of patients to that of healthy controls is given by

$$
\frac{B P_{S Z}}{B P_{H C}}=\frac{B_{\max , S Z}}{B_{\max , H C}} \frac{K_{D A}+[D A]_{H C}}{K_{D A}+[D A]_{S Z}}
$$

for both before and after AMPT. Here the dissociate constant for DA, $K_{D A}$, is also assumed to be unchanged in schizophrenia patients. The occupancy of the D2 receptor by DA is given by

$$
P=\frac{[D A]}{K_{D A}+[D A]}
$$

Using BP data obtained from receptor imaging studies, we are able to estimate the receptor occupancies for both schizophrenia patients and healthy controls.

\section{Circuit model}

The circuit model consists of the three brain regions; i.e., the PFC, the striatum, and the midbrain DA nuclei such as the substantia nigra and the ventral tegmental area (Fig. 1). It includes the effects of the stimulation of $\mathrm{D} 2$ receptors at the glutamatergic terminals of the frontostriatal projection and the autoreceptors on the dopaminergic terminals in the striatum. The dynamics of the population activities of the brain regions, the DA release in the striatum, and D2 receptor occupancy are given by

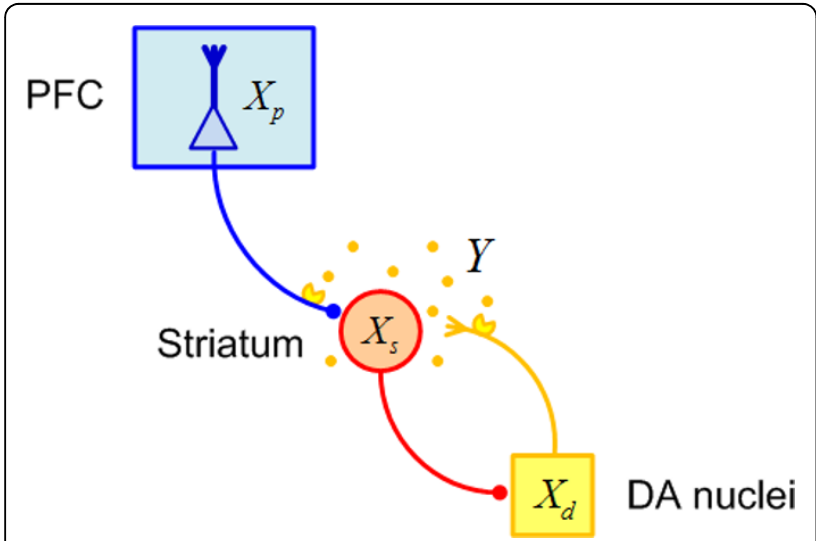

Figure 1 Circuit diagram of the frontostriatal system. The frontostriatal projection is glutamatergic (blue) and the axons from the striatal neurons to the midbrain DA neurons are GABAergic (red). D2 receptors are depicted at the terminals of the frontostriatal axon and the dopaminergic fiber in the striatum. Dots around the striatal neuron represent DA, which is released from the dopaminergic fiber (yellow).

$$
\begin{aligned}
\frac{d x_{s}}{d t} & =(1-b P) W_{p s} f\left(x_{p}\right)-\frac{x_{s}}{\tau_{s}} \\
\frac{d x_{d}}{d t} & =\frac{I_{d}-x_{d}}{\tau_{d}}-W_{s d} f\left(x_{s}\right) \\
\frac{d y}{d t} & =(1-a P) W_{d y} f\left(x_{d}\right)-\frac{y}{\tau_{y}} \\
P & =\frac{y}{K_{D A}+y}
\end{aligned}
$$

The symbols used in the equations are also listed in Table 1.

In the equilibrium state $(d / d t=0)$, we have

$$
\begin{aligned}
\frac{x_{s}}{\tau_{s}} & =(1-b P) W_{p s} f\left(x_{p}\right) \\
\frac{x_{d}}{\tau_{d}} & =\frac{I_{d}}{\tau_{d}}-W_{s d} f\left(x_{s}\right) \\
\frac{y}{\tau_{y}} & =(1-a P) W_{d y} f\left(x_{d}\right)
\end{aligned}
$$

Using the linear approximation of the activation function $f(x) \approx x$ and introducing new variables: $X_{p} \equiv \tau_{s} \tau_{d} \tau_{y} W_{p s} W_{s d} W_{d y} x_{p} / K_{D A}, X_{s} \equiv \tau_{d} \tau_{y} W_{s d} W_{d y} x_{s} / K_{D A}$, $X_{d} \equiv \tau_{y} W_{d y} x_{d} / K_{D A}, J_{d} \equiv \tau_{y} W_{d y} I_{d} / K_{D A}$, and $Y \equiv y / K_{D A}$, we rewrite the above equations as

$$
\begin{aligned}
X_{s} & =(1-b P) X_{p} \\
X_{d} & =J_{d}-X_{s} \\
Y & =(1-a P) X_{d} \\
P & =\frac{Y}{1+Y}
\end{aligned}
$$

From these equations, we have the relationships between $X_{p}$ and $X_{s}$ as well as between $X_{p}$ and $Y$ as

$$
\begin{aligned}
& X_{p}=\frac{1+Y}{1+(1-b) Y} X_{s} \\
& X_{p}=\frac{1+Y}{1+(1-b) Y}\left[J_{d}-\frac{(1+Y) Y}{1+(1-a) Y}\right]
\end{aligned}
$$

or

$$
\begin{aligned}
& X_{p}=\frac{1}{1-b P} X_{s} \\
& X_{p}=\frac{1}{1-b P}\left[J_{d}-\frac{P}{(1-P)(1-a P)}\right]
\end{aligned}
$$

The variables have the physiological constraints that all of them are positive $\left(X_{p}, X_{s}, X_{d}, Y>0\right)$ 


\section{Results}

\section{The frontostriatal system}

Figure 2 shows the relationships between $X_{p}$ and $X_{s}$ as well as $X_{p}$ and $Y$, which are given by Eq. (8), with five different values of the D2 receptor activation coefficient $(b=0,0.25,0.5,0.75,1.0)$. We assumed $J_{d}=1$ for simplicity. The activation of the D2 receptor decreases $X_{s}$ and increases $Y$. As a result, the $X_{s}$ vs $X_{p}$ curve is convex downward and the $Y$ vs $X_{p}$ curve is convex upward as shown in Fig. 2. The amount of the enhancement of the DA release is generally large; it is $0.55(b=1.0)$ compared to $0.30(b=0)$ when $X_{p}=0.7$. That is, for the modest activation of the PFC, the DA release increases by $83 \%$ when the coefficient of the D2 receptor stimulation increases from 0.0 to 1.0 .

The effects of autoreceptor activation, which are also given by Eq. (8), are depicted in Fig. 3. The effect on the activity of the striatum, $X_{s}$, is small (Fig. $3 a)$. The autoreceptor activation reduces the DA release, and this effect is larger when the activity of the PFC, $X_{p}$, becomes lower (Fig. 3b). For example, the amount of DA release is 0.30 without D2 heteroand autoreceptors, 0.55 with only the D2 heteroreceptor, and 0.50 with both the hetero- and autoreceptors (Table 2).

\section{Dopamine depletion}

The occupancy of D2 receptors in the striatum was estimated from the results of DA depletion studies [22,34-38]. The estimated occupancies are summarized in Table 3. There is only one study at present that gives the occupancy in both healthy subjects and schizophrenia patients [22]. The others studied either schizophrenia patients or healthy subjects. Because there is considerable variability in the occupancy among studies, we here set two models as follows.

\section{Model 1}

The first model comes from the study [22]. The D2 receptor occupancy is estimated to be $12 \%$ in healthy subjects and $21 \%$ in schizophrenia patients by assuming the DA depletion of $70 \%$. The relative value of the D2 receptor density, $B_{\max }$, is also estimated to be 1.0 in the healthy subjects and 1.2 in the patients. In this case, the extracellular DA concentration normalized by the dissociation constant, $Y=[D A] / K_{D A}$, is 0.136 in the healthy subjects and 0.266 in the patients.

\section{Model 2}

The second model comes from averaging of the results for healthy subjects because there are several different studies from healthy subjects. The averaged D2 occupancy is $23.6 \%$. From the ratio of HC: $\mathrm{SZ}=12 \%: 21 \%$ in Model 1, this extrapolates to the D2 receptor occupancy in patients of $23.6 \% \times 21 / 12=41.3 \%$. Model 2 , therefore, uses the values of $24 \%$ and $41 \%$ for healthy subjects and patients, respectively. The relative values of are assumed to be the same with Model 1. In Model 2, the extracellular DA concentration normalized by the dissociation constant, $Y=[D A] / K_{D A}$, is 0.316 in healthy subjects and 0.695 in schizophrenia patients. These results are summarized in Table 4.

\section{Schizophrenia patients vs healthy subjects}

In this section, we compare the dependences of the glutamatergic synaptic efficacy and the PFC activity on the
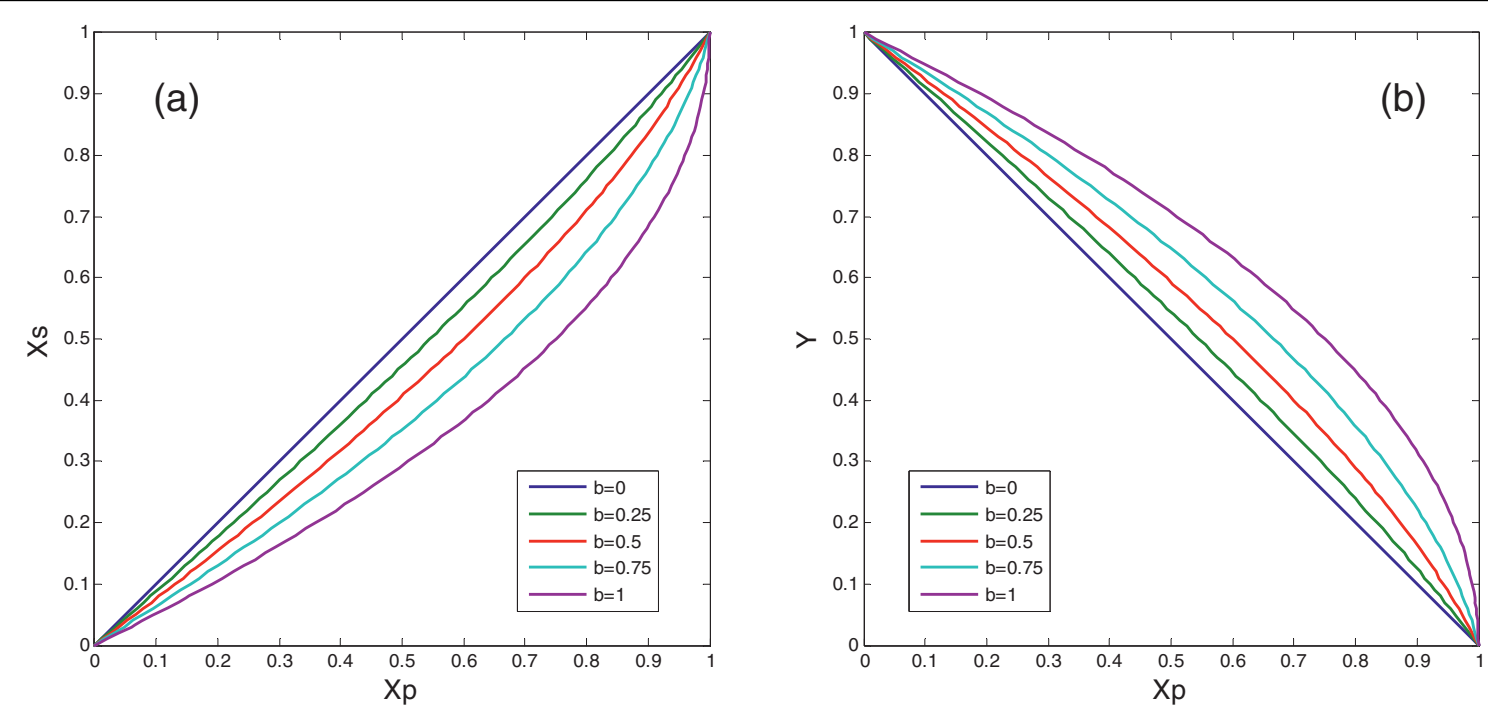

Figure 2 Dependences of the striatal activity, $\boldsymbol{X}_{\boldsymbol{s}}$, and the normalized DA release, $\boldsymbol{Y}$, on PFC activity, $\boldsymbol{X}_{\boldsymbol{p}}$. The D2 effects become larger for higher values of $b$, the coefficient representing the presynaptic depression of the frontostriatal glutamatergic neurotransmission by D2 receptor activation. 

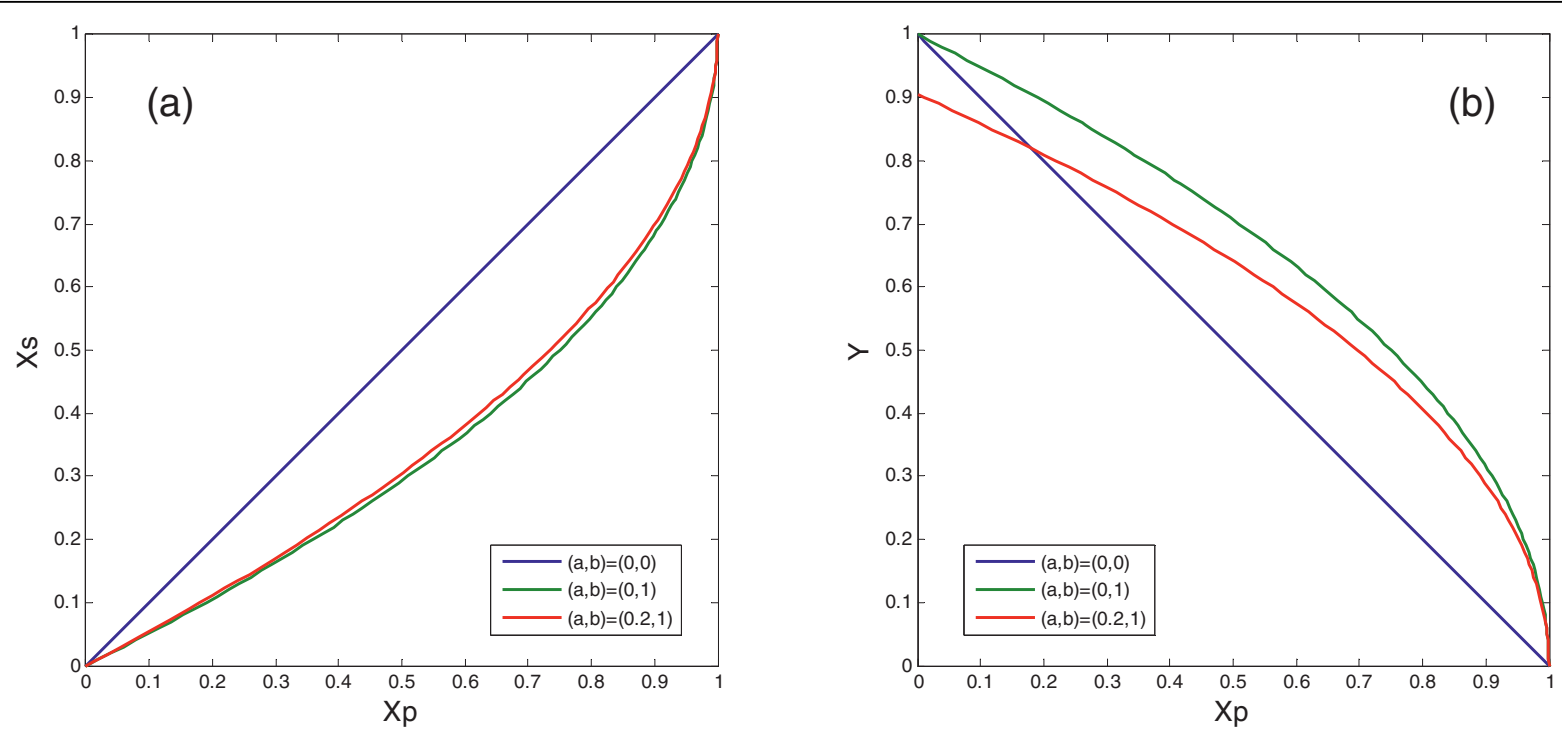

Figure 3 Effects of the activation of the D2 receptors on the striatal activity, $X_{s}$, and the normalized DA release, $Y$. The effect of the D2 autoreceptors on the dopaminergic fibers from the midbrain is specified by $a$. The effect of the D2 receptors on the glutamatergic terminals from PFC pyramidal neurons is specified by $b$.

Table 2 Striatal population activity, $X_{s,}$ and DA release, $Y$, for different D2 effects (representing by the coefficients of $a$ and $b$ ) when the PFC is modestly activated $\left(X_{p}=0.7\right)$

\begin{tabular}{ccccc}
\hline & & $\mathbf{a}=\mathbf{0}$ & $\mathbf{a}=\mathbf{0 . 2}$ \\
\cline { 2 - 5 } & $\mathbf{b}=\mathbf{0}$ & & $\mathbf{b}=\mathbf{1}$ \\
\hline$X_{5}$ & 0.7 & 0.45 & 0.46 \\
$Y$ & 0.3 & 0.55 & 0.5 \\
\hline
\end{tabular}

Table 3 Striatal D2 receptor occupancies estimated from the receptor imaging studies

\begin{tabular}{ccl}
\hline \multicolumn{2}{l}{ D2 occupancy } & \\
HC & SZ & References \\
\hline $12 \%$ & $21 \%$ & Abi-Dargham et al. (2000) [22] \\
$45 \%$ & - & Erlandsson et al. (2003) [35] \\
$26 \%$ & - & Laruelle et al. (1997) [34] \\
$13 \%$ & - & Riccardi et al. (2008) [36] \\
$22 \%$ & - & Verhoeff et al. (2001) [37] \\
- & $16 \%$ & Voruganti et al. (2001) [38] \\
\hline
\end{tabular}

average $\quad 23.6 \%$

There is only one study at present that gives the occupancy in both healthy subjects and schizophrenia patients.

D2 receptor activation between schizophrenia patients and healthy subjects. Because the results will be different between Model 1 and Model 2, we analyze them one by one. From Eq. (9), the normalized frontostriatal synaptic weight or the glutamatergic synaptic efficacy and the PFC activity are given by

$$
\begin{aligned}
& V_{p s}=1-b P \\
& X_{p}=\frac{1}{1-b P}\left[J_{d}-\frac{P}{(1-P)(1-a P)}\right]
\end{aligned}
$$

And we have the differences of $V_{p s}$ and between patients and healthy subjects as

$$
\begin{aligned}
\Delta V_{p s} & =(1-b P)_{S Z}-(1-b P)_{H C}=(b P)_{H C}-(b P)_{S Z} \\
\Delta X_{p} & =\left(\frac{1}{1-b P}\left[1-\frac{P}{(1-P)(1-a P)}\right]\right)_{S Z} \\
& -\left(\frac{1}{1-b P}\left[1-\frac{P}{(1-P)(1-a P)}\right]\right)_{H C}
\end{aligned}
$$

Because $B_{\max }=1.0(\mathrm{HC})$ vs $1.2(\mathrm{SZ})$, the values of $a$ and $b$ in patients should be 1.2 times of those in healthy subjects. Both the differences given by Eq. (11) in Model 1 are depicted in Fig. 4. They are depicted against the D2 receptor activation coefficient, $b$, with different values of the autoreceptor activation coefficient, $a$. The difference in the normalized frontostriatal synaptic weight does not depend on the autoreceptor activation coefficient as shown in Eq. (11) (Fig. 4a). On the other hand, the PFC activity depends on the autoreceptor activation coefficient (Fig. 4b). Figure 5 shows the differences of the normalized frontostriatal synaptic weight and the PFC activity between schizophrenia patients and healthy subjects in Model 2. 
Table 4 Normalized D2 receptor densities, D2 receptor occupancies by DA, and normalized extracellular DA concentrations in healthy subjects (HC) and schizophrenia patients (SZ) in Model 1 and Model 2

\begin{tabular}{ccccc}
\hline & \multicolumn{2}{c}{ Model 1 } & \multicolumn{2}{c}{ Model 2 } \\
& HC & SZ & HC & SZ \\
\hline$B_{\max }$ & 1 & 1.2 & 1 & 1.2 \\
$P$ & $12 \%$ & $21 \%$ & $24 \%$ & $41 \%$ \\
{$[D A] / K_{D A}$} & 0.136 & 0.266 & 0.316 & 0.695 \\
\hline
\end{tabular}

Optimum D2 receptor occupancy by antipsychotics

The administration of an antipsychotic drug causes competitive binding at D2 receptors. The occupancy of the D2 receptor by endogenous DA under the existence of an antipsychotic drug is given by

$$
P_{D A(A P D)}=\frac{\frac{Y}{K_{D A}}}{1+\frac{Y}{K_{D A}}+\frac{F}{K_{A P D}}}
$$

The above equation shows that the occupancy of the D2 receptor by endogenous DA is generally reduced by the competitive binding with the antipsychotic drug. Similarly, the occupancy of the D2 receptor by the administered antipsychotic drug is given by

$$
P_{A P D}=\frac{\frac{F}{K_{A S D}}}{1+\frac{Y}{K_{D A}}+\frac{F}{K_{A P D}}}
$$

We here assume that the optimum D2 antagonistic effect of antipsychotic drugs is expected when the net binding of endogenous DA to the D2 receptor in schizophrenia patients is reduced to that in healthy controls, that is

$$
B_{\max , S Z} P_{D A(A P D), S Z}=B_{\max , H C} P_{D A, H C}
$$

or

$$
P_{D A(A P D), S Z}=\frac{B_{\max , H C}}{B_{\max , S Z}} P_{D A, H C}
$$

From Table 4 , where $\mathrm{P}_{D A, H C}$ is $12 \%$ in Model 1 and $24 \%$ in Model 2, the left hand side of the above equation is $10 \%$ in Model 1 and $20 \%$ in Model 2. Using Eqs. (12) and (13) as well as the values of $[D A] / K_{D A}$ in Table 4, we estimate the optimum free extracellular concentration of the antipsychotic drug divided by the dissociation constant and the occupancy of the D2 receptor by the administered antipsychotic drug as $\left(F_{\text {opt }}\right)$ $\left.K_{A P D}, \mathrm{P}_{A P D}\right)=(1.39,52.3 \%)$ in Model 1 and $(1.78$, $51.2 \%)$ in Model 2. The optimum antipsychotic effect requires the dose of an administrating drug that is higher in Model 2 than in Model 1. However, the occupancy of the D2 receptor by the administered drug is slightly lower in Model 2. This is because the DA release in Model 2 is higher than in Model 1. The total occupancy by DA and the drug, $P_{D A(A P D), S Z}+$ $P_{A P D}$, is also higher in Model 2, which is $71.2 \%$ versus 62.3\% in Model 1.
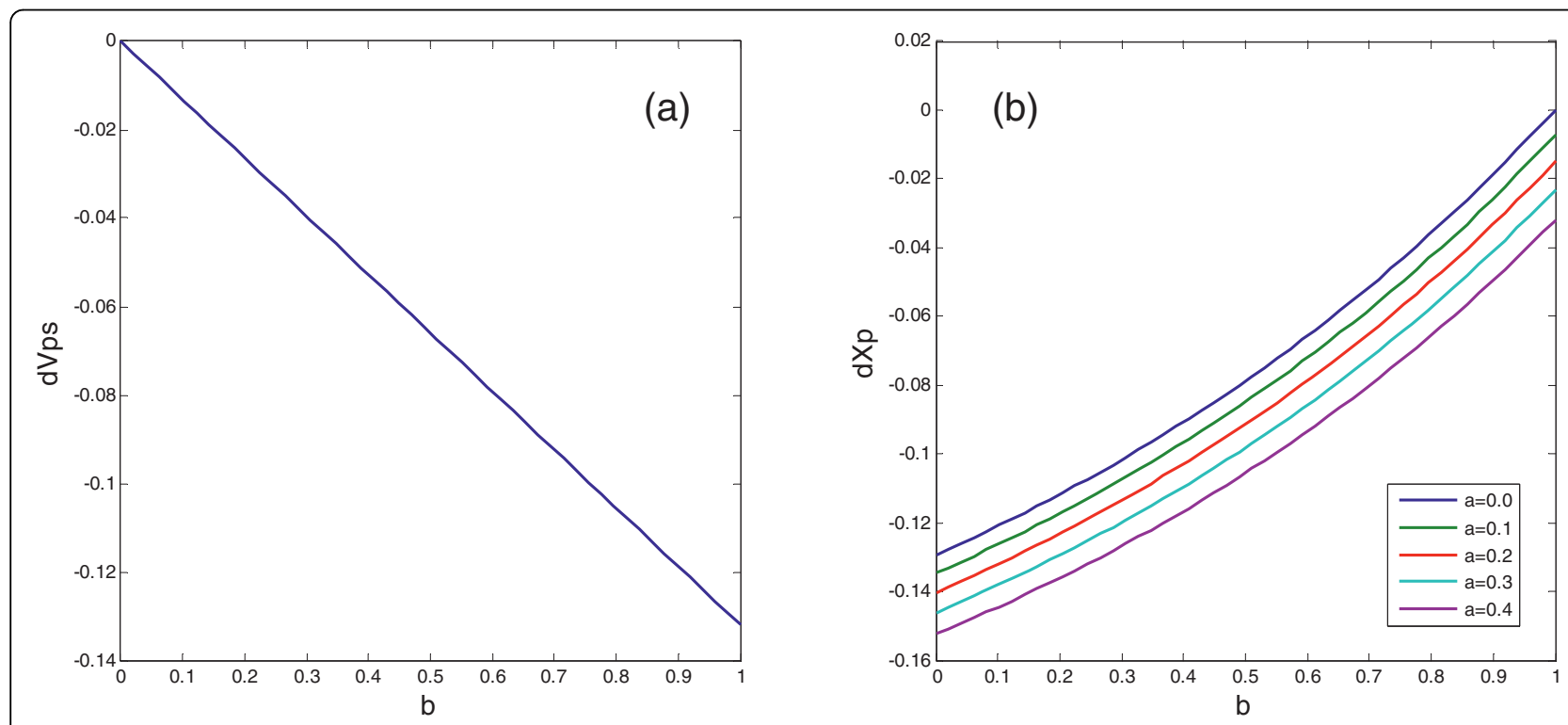

Figure 4 Differences of the normalized glutamatergic synaptic efficacy and the PFC activity between schizophrenia patients and healthy subjects (i.e., those in SZ - those in HC), which are given by Eq. (11), in Model 1. 

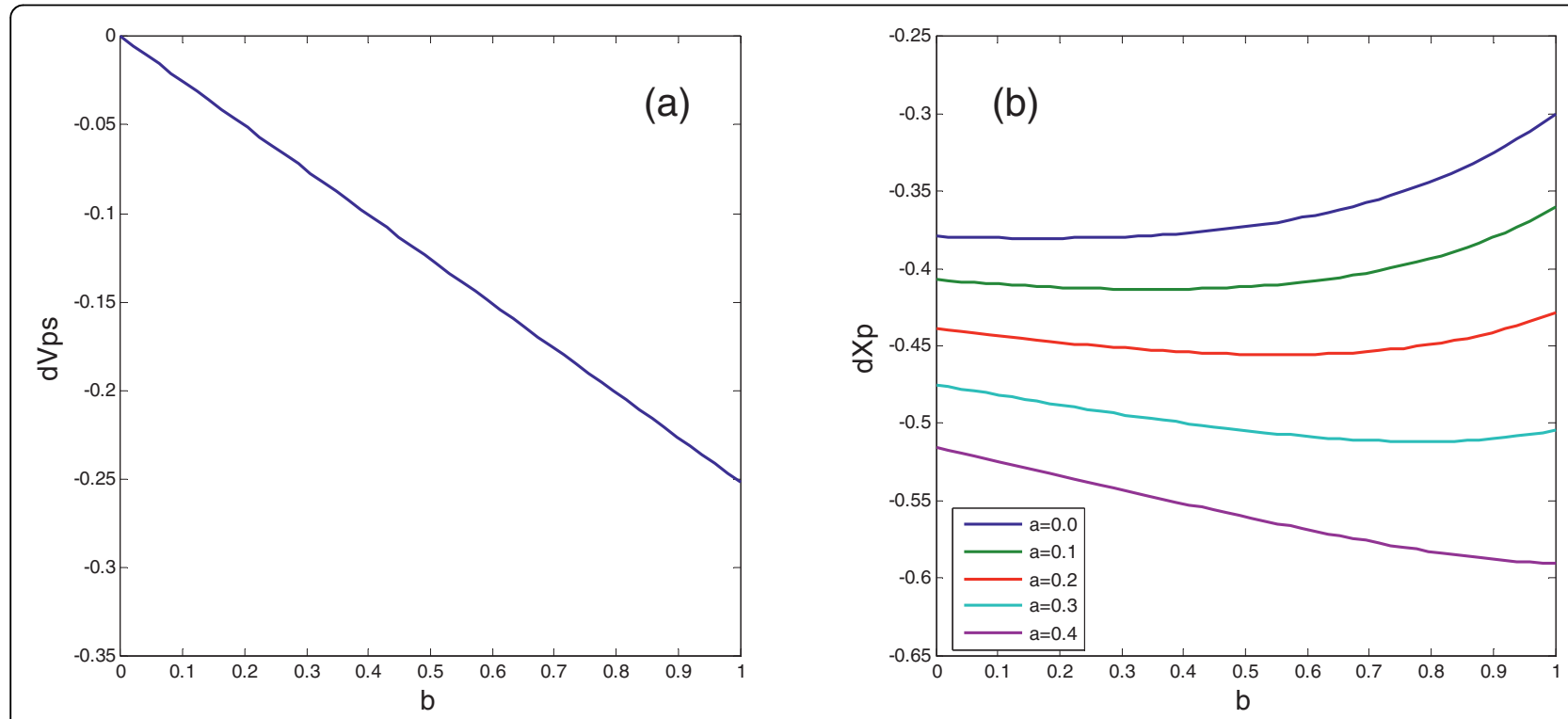

Figure 5 Differences of the normalized glutamatergic synaptic efficacy and the PFC activity between schizophrenia patients and healthy subjects (i.e., those in SZ - those in HC), which are given by Eq. (11), in Model 2.

\section{Prediction of clinical outcome}

Abi-Dargham et al. [22] conducted 6-week antipsychotic medication of inpatients of schizophrenia $(n=14)$. The drugs used were olanzapine $(n=8)$, risperidone $(n=2)$, quetiapine $(n=2)$, clozapine $(n=1)$, and haloperidol $(n=1)$; benzodiazepine medications were added as needed. They measured AMPT-induced increases in D2 receptor BP before treatment and PANSS scores one and six weeks after treatment. The increase in D2 receptor $\mathrm{BP}$ induced by the acute administration of AMPT into the patients had a significant positive correlation with the improvement of positive symptoms after 6 weeks of the antipsychotic treatment $\left(R^{2}=0.58, p=0.0015\right)$. Changes in negative symptoms were not statistically significant. We have estimated the D2 receptor occupancy from the BP data. Our model describes the relationship between PFC activity and D2 receptor binding: Eq. (10) relates the PFC activity to the D2 receptor occupancy, which is given by Eq. (4). The extracellular DA concentration in Eq. (4) is obtained from Eq. (2) as

$$
\begin{aligned}
& Y=\frac{[D A]}{K_{D A}}=\frac{\frac{B P_{A M P T}-B P}{B P}}{1-\frac{[D A]_{A M P T}}{[D A]} \frac{B P_{A M P T}}{B P}}=\frac{\beta}{1-\alpha(1+\beta)} \\
& \alpha=\frac{[D A]_{A M P T}}{[D A]}, \quad \beta=\frac{B P_{A M P T}-B P}{B P}
\end{aligned}
$$

Using the assumption of $\alpha=0.3$ and the $\beta$ values from Fig. 3 of [22], the improvement of positive symptoms can be associated with the PFC activity, as shown in Fig. 6. The regression model obtained from this transformed data set is $\Delta$ PANSSp $=49.6 X_{p}-61.5$ $\left(R^{2}=0.56, p=0.002\right)$, where $\Delta$ PANSSp is the change in the PANSS subscale for positive symptoms. This model suggests that patients with lower PFC activity tend to have greater improvement of positive symptoms following subchronic (six weeks) antipsychotic treatment (note that $\Delta$ PANSSp $=49.6 X_{p}-61.5<0$ for improvement).

\section{Discussion}

The model in this article describes the inverse relationship between the PFC activity and the extracellular DA level in the striatum. This inverse relationship is accounted for by the circuitry of the frontostriatal system with dopaminergic innervation. The circuitry is consistent with anatomical study [39]. Functional neuroimaging studies $[10,40]$ showing hypoactivation of both the PFC and the striatum during task performance, such as an oddball task and a working memory task, in schizophrenia patients also support this circuit model. Dysregulation of the frontostriatal system is responsible for the deficits in cognitive functions, including executive functions, in schizophrenia patients [41,42]. This article explored how much degree the circuit property of the frontostriatal system, which links the regional activities of the frontostriatal system and the striatal DA function, is relevant to schizophrenia. 


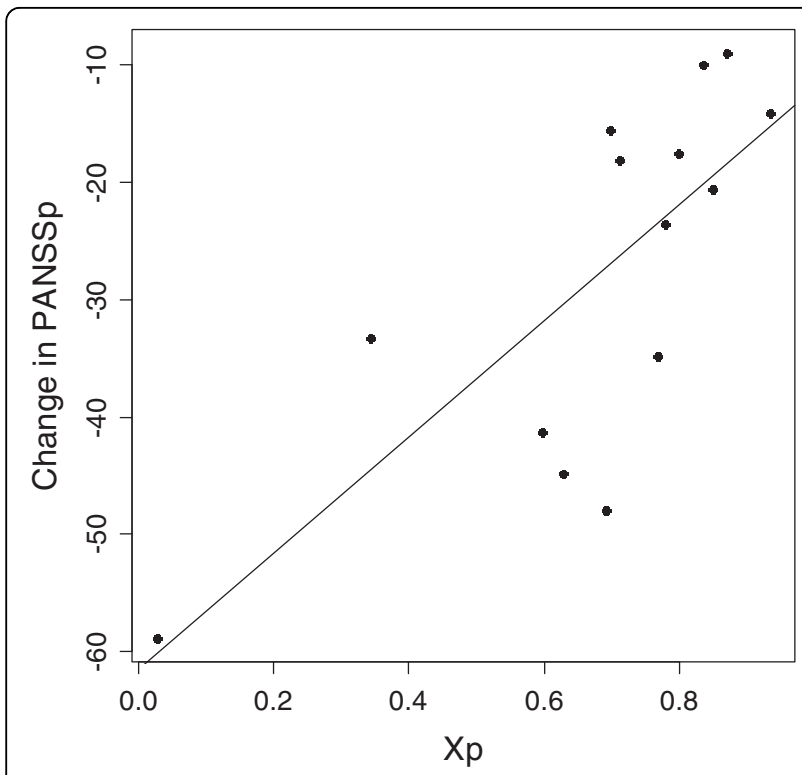

Figure 6 Relationship between the change in the PANSS subscale for positive symptoms and the PFC activity, $X_{p}$, when $(\boldsymbol{a}, \boldsymbol{b})=(\mathbf{0}, \mathbf{0})$. The regression line is $\triangle$ PANSSP $=49.6 X_{p}-61.5$ $\left(R^{2}=0.56, p=0.002\right)$.

The model describes that the stimulation of D2 receptors at the terminals of the frontostriatal projection enhances the striatal DA level due to the suppression of the glutamatergic input to GABAergic striatal neurons. With this model, the amount of elevation of the striatal DA level was estimated: When the PFC is modestly activated $\left(X_{p}=0.7\right.$ in this model), the amount of DA elevation is maximally $83 \%$ when assuming $b=1.0$ (i.e., 1.83 times larger compared with the case of no D2 receptor activation or $b=0$ ). This elevation is reduced to $67 \%$ when D2 autoreceptors on the dopaminergic terminals are taken into account (assuming $a=0.2$ in the model). The DA level might further be enhanced with increased proportions of the high-affinity states of D2 receptors, though this has not been taken into account in the model.

This study used receptor imaging data to estimate the amount of the DA release in the striatum in schizophrenia patients and healthy subjects. The result was then taken into the network model to calculate the glutamatergic input to the striatum and the population activity of the striatal neurons. It was thus possible to assume that the strength of D2 receptor activation is proportional to the D2 receptor occupancy by DA rather than the extracellular DA concentration. The combination of this model and the published receptor imaging data of schizophrenia patients and healthy controls enabled us to compare PFC activity that accounted for the alterations in the D2 receptor binding by endogenous DA in the striatum. The results suggest that the PFC population activity is reduced in schizophrenia patients, which is consistent with the hypofrontality hypothesis. Hypofrontality actually has unresolved issues; for example, on glutamatergic and GABAergic neurotransmission. In this article, however, the term is used to represent simply a reduction of the population activity of the PFC. The estimated amount of the reduction of the population activity depends on the $\mathrm{D} 2$ receptor occupancy by DA, which varies largely across the studies that have ever been made. Because the results of receptor imaging studies have a large variability, this article has chosen two model cases that could be representatives of the results. The reason that Model 2 led to a much larger difference in the PFC activity between patients and controls is that the experimentally estimated D2 receptor binding is higher than that in Model 1. Further accumulation of receptor imaging data would make this estimation more precise.

We have estimated the 'optimum' D2 receptor occupancy by an antipsychotic drug to be $52 \%$. The estimation of the optimum occupancy of an antipsychotic drug is based on the assumption that the net binding of endogenous DA to the D2 receptors should be the same with that of healthy controls. Similar estimation was made previously [43], in which the authors made the assumption that the D2 receptor occupancy by DA should be the same with that of healthy controls and obtained the D2 receptor occupancy by an antipsychotic drug of $48 \%$. This is slightly lower than our estimation because this estimation did not take the upregulation of D2 receptors into account. It is interesting to compare the estimated value of $52 \%$ with the measured occupancies of various antipsychotic drugs (Fig. 7 of [44]). The occupancies of many antipsychotic drugs are higher than this level and mostly in the range of $60-80 \%$. The motor (extrapyramidal) side effects become prominent when the occupancy exceeds 75-80\% [45]. Unlike other drugs, clozapine and quetiapine have the occupancies in the striatum that are mostly lower than $50 \%$. The occupancy by quetiapine is lower than the occupancy by clozapine [46]. Therapeutic effects of these drugs appear to be achieved at the occupancy threshold that is lower than those of other antipsychotic drugs [46]. For other drugs, the occupancy should be lower than $75 \%$ to avoid extrapyramidal side effects. On the other hand, subjective well-being appeared to have a negative correlation with the striatal D2 receptor occupancy [47]. Therefore, the D2 receptor occupancy by many of the antipsychotic drugs should be in the range of $50-75 \%$ with a tradeoff between the efficacy and subjective experience. Agid et al. [23] examined the relationship between striatal and extrastriatal D2 occupancies by antipsychotic drugs and clinical effects, showing that striatal D2 occupancy 
predicted response in positive psychotic symptoms but not negative symptoms and the prediction by striatal D2 blockade was better than frontal, temporal, and thalamic occupancy. Their result (Fig. 1 of [23]) shows that striatal D2 blockade with the occupancy higher than $50 \%$ has a practical therapeutic effect on positive symptoms.

Schizophrenia patients with higher striatal D2 receptor occupancy tended to have greater improvement of positive symptoms after antipsychotic treatments [22]. If the hyperdopaminergic tone in the striatum is caused primarily by PFC hypoactivity, this would further indicate that hypofrontality could also be predictive of good response of positive symptoms to antipsychotic medication. This article examined this predictability of the model by using published data. The result shows that patients with lower PFC activity have larger improvements of positive symptoms as measured with PANSS positive scores. Hypofrontality has been generally associated with cognitive and negative symptoms in schizophrenia [1-9]. By linking hypofrontality to striatal hyperdopaminergic neurotransmission, the frontostriatal model proposed in this article has associated hypofrontality with the therapeutic effect on positive symptoms. This is testable by a combination of fMRI studies and clinical studies. Furthermore, a multivariate analysis of a data set from the combination of fMRI and PET receptor imaging studies will test the frontostriatal model more directly.

\section{Conclusion}

This article described theoretically the relationship between regional activities in the frontostriatal system and striatal DA release. These quantities were compared between schizophrenia patients and healthy subjects by using the results from receptor binding studies. The results are consistent with hypofrontality. This study also predicts that patients with lower PFC activity tend to have greater improvement of positive symptoms following antipsychotic medication. The 'optimum' D2 receptor occupancy by antipsychotic drugs was estimated to be $52 \%$.

\section{Acknowledgements}

This study was supported by the Sophia University Open Research Center grant: Human Information Science.

\section{Authors' contributions \\ ST is the sole author of this study. He designed the study, directed the modeling and analysis and wrote the paper.}

\section{Competing interests}

The author declares that he has competing interests.

Received: 19 May 2009 Accepted: 27 February 2010 Published: 27 February 2010
References

1. Hill K, Mann L, Laws KR, Stephenson CME, Nimmo-Smith I, McKenna PJ: Hypofrontality in schizophrenia: a meta-analysis of functional imaging studies. Acta Psychiatrica Scandinavica 2004, 110(4):243-256.

2. Carter CS, Perlstein P, Ganguli R, Brar J, Mintun M, Cohen JD: Functional hypofrontality and working memory dysfunction in schizophrenia. Am J Psychiatry 1998, 155:1285-1287.

3. Perlstein WM, Carter CS, Noll DC, Cohen JD: Relation of prefrontal cortex dysfunction to working memory and symptoms in schizophrenia. Am J Psychiatry 2001, 158(7):1105-1113

4. Riehemann S, Volz HP, Stützer P, Smesny S, Gaser C, Sauer H: Hypofrontality in neuroleptic-naive schizophrenic patients during the Wisconsin Card Sorting Test-a fMRI study. Eur Arch Psychiatry Clin Neurosci 2001, 251(2):66-71.

5. Weinberger DR, Berman KF, Zec RF: Physiologic Dysfunction of Dorsolateral Prefrontal Cortex in Schizophrenia: I. Regional Cerebral Blood Flow Evidence. Arch Gen Psychiatry 1986, 43(2):114-124.

6. Wolkin A, Sanfilipo M, Wolf AP, Angrist B, Brodie JD, Rotrosen J: Negative symptoms and hypofrontality in chronic schizophrenia. Arch Gen Psychiatry 1992, 49(12):959-965.

7. Andreasen NC, O'Leary DS, Flaum M, Nopoulos P, Watkins GL, Boles Ponto LL, Hichwa RD: Hypofrontality in schizophrenia: distributed dysfunctional circuits in neuroleptic-naive patients. Lancet 1997 349(9067):1730-1734.

8. Whalley HC, Mowatt L, Stanfield AC, Hall J, Johnstone EC, Lawrie SM, Mclntosh AM: Hypofrontality in subjects at high genetic risk of schizophrenia with depressive symptoms. Journal of Affective Disorders 2008, 109(1):99-106.

9. Park $\mathrm{H}$, Kim JJ, Chun J, Jung YC, Seok JH, Park HJ, Lee JD: Medial prefrontal default-mode hypoactivity affecting trait physical anhedonia in schizophrenia. Psychiatry Research: Neuroimaging 2009, 171(3):155-165.

10. Morey RA, Inan S, Mitchell TV, Perkins DO, Lieberman JA, Belger A: Imaging frontostriatal function in ultra-high-risk, early, and chronic schizophrenia during executive processing. Arch Gen Psychiatry 2005, 62(3):254-262.

11. Whalley HC, Simonotto E, Moorhead W, McIntosh A, Marshall I, Ebmeier KP, Owens DG, Goddard NH, Johnstone EC, Lawrie SM: Functional imaging as a predictor of schizophrenia. Biol Psychiatry 2006, 60(5):454-462.

12. Molina V, Sanz J, Reig S, Martinez R, Sarramea F, Luque R, Benito C, Gispert J, Pascau J, Desco M: Hypofrontality in men with first-episode psychosis. Br J Psychiatry 2005, 186:203-208.

13. Thermenos HW, Goldstein JM, Buka SL, Poldrack RA, Koch JK, Tsuang MT, Seidman LJ: The effect of working memory performance on functional MRI in schizophrenia. Schizophr Res 2005, 74(2-3):179-194.

14. Glahn DC, Ragland JD, Abramoff A, Barrett J, Laird AR, Bearden CE, Velligan DI: Beyond hypofrontality: A quantitative meta-analysis of functional neuroimaging studies of working memory in schizophrenia. Hum Brain Mapp 2005, 25(1):60-69.

15. Manoach DS, Press DZ, Thangaraj V, Searl MM, Goff DC, Halpern E, Saper CB, Warach S: Schizophrenic subjects activate dorsolateral prefrontal cortex during a working memory task, as measured by fMRI. Biol Psychiatry 1999, 45:1128-1137.

16. Tanaka S: Dopaminergic control of working memory and its relevance to schizophrenia: a circuit dynamics perspective. Neuroscience 2006, 139:153-171.

17. Manoach DS, Halpern EF, Kramer TS, Chang Y, Goff DC, Rauch SL, Kennedy DN, Gollub RL: Test-retest reliability of a functional MRI working memory paradigm in normal and schizophrenic subjects. Am J Psychiatry 2001, 158(6):955-958

18. Haroutunian V, Knott $P$, Davis KL: Effects of mesocortical dopaminergic lesions upon subcortical dopaminergic function. Psychopharmacol Bull 1988, 24(3):341-344

19. Lipska BK, Weinberger DR: Cortical regulation of the mesolimbic dopamine system: implications for schizophrenia. Limbic motor circuits and neuropsychiatry Ch11 CRC Kalivas PW, Barnes CD 1993.

20. Meyer-Lindenberg A, Miletich RS, Kohn PD, Esposito G, Carson RE, Quarantelli M, Weinberger DR, Berman KF: Reduced prefrontal activity predicts exaggerated striatal dopaminergic function in schizophrenia. Nat Neurosci 2002, 5(3):267-271.

21. Kolachana BS, Saunders RC, Weinberger DR: Augmentation of prefrontal cortical monoaminergic activity inhibits dopamine release in the 
caudate nucleus: an in vivo neurochemical assessment in the rhesus monkey. Neuroscience 1995, 69(3):859-868.

22. Abi-Dargham A, Rodenhiser J, Printz D, Zea-Ponce Y, Gil R, Kegeles LS, Weiss R, Cooper TB, Mann JJ, Heertum RLV, et al: Increased baseline occupancy of D2 receptors by dopamine in schizophrenia. Proc Natl Acad Sci USA 2000, 97:8104-8109, [comments in Seeman and Kapur (2000) PNAS PMID: 10884398].

23. Agid O, Mamo D, Ginovart N, Vitcu I, Wilson AA, Zipursky RB, Kapur S: Striatal vs extrastriatal dopamine D2 receptors in antipsychotic response-a double-blind PET study in schizophrenia. Neuropsychopharmacology 2007, 32(6):1209-1215.

24. Nicola SM, Surmeier DJ, Malenka RC: Dopaminergic modulation of neuronal excitability in the striatum and nucleus accumbens. Annu Rev Neurosci 2000, 23:185-215.

25. Surmeier DJ, Song WJ, Yan Z: Coordinated expression of dopamine receptors in neostriatal medium spiny neurons. J Neurosci 1996, 16(20):6579-6591.

26. Bamford NS, Robinson S, Palmiter RD, Joyce JA, Moore C, Meshul CK: Dopamine modulates release from corticostriatal terminals. J Neurosci 2004, 24(43):9541-9552.

27. Bamford NS, Schmitz Y, Schumauss C, Zakharenko SS, Zablow L, Sulzer D: Heterosynaptic dopamine neurotransmission selects sets of corticostriatal terminals. Neuron 2004, 42(4):653-663.

28. Meador-Woodruff JH, Damask SP, Watson SJJ: Differential expression of autoreceptors in the ascending dopamine systems of the human brain. Proc Natl Acad Sci USA 1994, 91(17):8297-8301.

29. Wang H, Pickel VM: Dopamine D2 receptors are present in prefrontal cortical afferents and their targets in patches of the rat caudateputamen nucleus. I Comp Neurol 2002, 442:392-404.

30. Horvitz JC: Dopamine gating of glutamatergic sensorimotor and incentive motivational input signals to the striatum. Behav Brain Res 2002 137:65-74.

31. McGowan S, Lawrence AD, Sales T, Quested D, Grasby P: Presynaptic Dopaminergic Dysfunction in Schizophrenia: A Positron Emission Tomographic [18F] Fluorodopa Study. Arch Gen Psychiatry 2004, 61:134-142.

32. Brady AM, O'Donnell P: Dopaminergic modulation of prefrontal cortical input to nucleus accumbens in vivo. Journal of Neuroscience 2004, 24:1040-1049.

33. Slifstein $M$, Laruelle $M$ : Models and methods for derivation of in vivo neuroreceptor parameters with PET and SPECT reversible radiotracers. Nucl Med Biol 2001, 28(5):595-608.

34. Laruelle M, D'Souza CD, Baldwin RM, Abi-Dargham A, Kanes SJ, Fingado CL, Seibyl JP, Zoghbi SS, Bowers MB, Jatlow P, et al: Imaging D2 Receptor Occupancy by Endogenous Dopamine in Humans. Neuropsychopharmacology 1997, 17:162-174.

35. Erlandsson K, Bressan RA, Mulligan RS, Ell PJ, Cunningham VJ, Pilowsky LS Analysis of D2 dopamine receptor occupancy with quantitative SPET using the high-affinity ligand [1231] epidepride: resolving conflicting findings. Neuroimage 2003, 19:1205-1214.

36. Riccardi P, Baldwin R, Salomon R, Anderson S, Ansari MS, Li R, Dawant B, Bauernfeind A, Schmidt D, Kessler R: Estimation of Baseline Dopamine D2 Receptor Occupancy in Striatum and Extrastriatal Regions in Humans with Positron Emission Tomography with [18F] Fallypride. Biological psychiatry 2008, 63(2):241-244.

37. Verhoeff NP, Kapur S, Hussey D, Lee M, Christensen B, Psych C, Papatheodorou G, Zipursky RB: A simple method to measure baseline occupancy of neostriatal dopamine D2 receptors by dopamine in vivo in healthy subjects. Neuropsychopharmacology 2001, 25(2):213-223.

38. Voruganti L, Slomka P, Zabel P, Costa G, So A, Mattar A, Awad AG: Subjective effects of AMPT-induced dopamine depletion in schizophrenia: correlation between dysphoric responses and striatal D2 binding ratios on SPECT imaging. Neuropsychopharmacology 2001, 25(5):642-650.

39. Sesack SR, Carr DB: Selective prefrontal cortex inputs to dopamine cells: implications for schizophrenia. Physiol Behav 2002, 77(4-5):513-517.

40. Koch K, Wagner G, Nenadic I, Schachtzabel C, Schultz C, Roebel M, Reichenbach JR, Sauer H, Schlosser RGM: Fronto-striatal hypoactivation during correct information retrieval in patients with schizophrenia: An fMRI study. Neuroscience 2008, 153(1):54-62.
41. Pantelis C, Barnes TR, Nelson HE, Tanner S, Weatherley L, Owen AM, Robbins T: Frontal-striatal cognitive deficits in patients with chronic schizophrenia. Brain 1997, 120:1823-1843.

42. Robbins TW: The case of frontostriatal dysfunction in schizophrenia. Schizophr Bull 1990, 16(3):391-402.

43. Frankle WG, Gil R, Hackett E, Mawlawi O, Zea-Ponce Y, Zhu Z, Kochan LD, Cangiano C, Slifstein M, Gorman JM, et al: Occupancy of dopamine D2 receptors by the atypical antipsychotic drugs risperidone and olanzapine: theoretical implications. Psychopharmacology (Berl) 2004, 175:473-480

44. Seeman P, Tallerico T: Rapid release of antipsychotic drugs from dopamine D2 receptors: an explanation for low receptor occupancy and early clinical relapse upon withdrawal of clozapine or quetiapine. Am J Psychiatry 1999, 156(6):876-884

45. Kapur S, Zipursky R, Jones C, Remington G, Houle S: Relationship Between Dopamine D2 Occupancy, Clinical Response, and Side Effects: A DoubleBlind PET Study of First-Episode Schizophrenia. Am J Psychiatry 2000, 157:514-520.

46. Kessler RM, Ansari MS, Riccardi P, Li R, Jayathilake K, Dawant B, Meltzer HY: Occupancy of Striatal and Extrastriatal Dopamine D2 Receptors by Clozapine and Quetiapine. Neuropsychopharmacology 2006, 31(9):1991-2001.

47. Mizrahi R, Rusjan P, Agid O, Graff A, Mamo DC, Zipursky RB, Kapur S: Adverse Subjective Experience With Antipsychotics and Its Relationship to Striatal and Extrastriatal D2 Receptors: a PET Study in Schizophrenia. Am J Psychiatry 2007, 164(4):630-637.

\section{Pre-publication history}

The pre-publication history for this paper can be accessed here: [http://www.biomedcentral.com/1471-244X/10/17/prepub]

doi:10.1186/1471-244X-10-17

Cite this article as: Tanaka: Model-based parametric study of frontostriatal abnormalities in schizophrenia patients. BMC Psychiatry 2010 10:17

\section{Submit your next manuscript to BioMed Central and take full advantage of:}

- Convenient online submission

- Thorough peer review

- No space constraints or color figure charges

- Immediate publication on acceptance

- Inclusion in PubMed, CAS, Scopus and Google Scholar

- Research which is freely available for redistribution

Submit your manuscript at www.biomedcentral.com/submit
C Biomed Central 